\title{
BRASIL: UN PAÍS EN COMPÁS DE ESPERA*
}

\author{
Brazil: A Country at a Standstill
}

\section{PEDRO FLORIANO RIBEIRO}

Celso Furtado Visiting Professor, University of Cambridge

Universidade Federal de São Carlos (UFSCar)

\author{
AMANDA VIZONÁ \\ Universidade Federal de São Carlos (UFSCar) \\ PRISCILLA LEINE CASSOTTA
}

Universidade Federal de São Carlos (UFSCar)

\begin{abstract}
RESUMEN
El 2015, primer año del segundo mandato de Dilma Rousseff, fue marcado por escándalos de corrupción, crisis económica y política. Ese escenario comienza a desenvolverse con las elecciones presidenciales de 2014, las más apretadas de la historia brasileña. La disonancia entre promesas de campaña, crisis económica y las revelaciones de la Operación Lava Jato afectaron la popularidad de la Presidenta, proporcionando munición para la oposición, que pasó a conducir una campaña proimpeachment. El gobierno se enfrentó a grandes dificultades para articular su coalición e implementar sus políticas, aun después de una reforma en el gabinete de ministros. El artículo analiza los fundamentos económicos y políticos de este escenario que colocó el país en situación de espera e incertidumbres. Las conclusiones discuten algunas de las implicaciones de la crisis en términos de calidad de la democracia y retos de los próximos años.
\end{abstract}

Palabras clave: Brasil, crisis económica, relaciones Ejecutivo-Legislativo, partidos, elecciones.

\begin{abstract}
The year of 2015, first year of Rousseff's second term, was marked by corruption scandals, economic and political crisis. This scenario begins to unfold with the 2014 presidential elections, the tightest in the Brazilian history. The divergence between campaign promises, economic crisis and revelations of Lava Jato Operation has affected president's approval ratings, giving ammunition to opposition to start a pro-impeachment campaign. The government has found it difficult to articulate their coalition and to implement its agenda, even after a cabinet reform. This article seeks to analyze economic and political fundamentals of this scenario that brought Brazil to a standstill. The findings discuss some of the implications of the crisis in terms of quality of democracy and challenges to be faced in the coming years.
\end{abstract}

Key words: Brazil, economic crisis, Executive-Legislative relations, parties, elections.

* La redacción del artículo fue concluida en marzo de 2016. En mayo, la presidenta Dilma Rousseff fue suspendida de sus funciones (por hasta 180 días), tras votaciones en la Cámara y Senado que decidieron la continuidad del proceso de impeachment contra ella, con base en la práctica de los "pedaleos fiscales". Tras su suspensión, el vicepresidente Michel Temer asumió las funciones de Presidente interino. 
"Cada vez que entramos en una crisis es el absurdo total, comprendé que la dialéctica solo puede ordenar los armarios en los momentos de calma".

Julio Cortázar

(Rayuela, 1963, cap. 28)

\section{INTRODUCCIÓN**}

El largo año de 2015 empezó en Brasil en la noche de 26 de octubre de 2014, cuando el Tribunal Superior Electoral (TSE) anunció la reelección de la presidenta Dilma Rousseff para otros cuatro años al frente del gobierno federal. Tras una campaña electoral bastante agresiva y polarizada, la candidata del Partido dos Trabalhadores (PT), sucesora de Luiz Inácio Lula da Silva, había derrotado a Aécio Neves, del Partido da Social Democracia Brasileira (PSDB). Fue la disputa más apretada por la Presidencia en la historia democrática del país: los 3,4 millones de votos de diferencia representaban poco más de $3 \%$ de los votos válidos de la segunda vuelta. A pesar de la derrota, los resultados confirmaron el proceso de fortalecimiento de la oposición en su tentativa de interrumpir la secuencia de gobiernos liderados por el PT -vencedor de los comicios en 2002 y 2006 con Lula, y en 2010 con Dilma-. Animada con el crecimiento electoral y respondiendo a sus bases más radicalizadas, la oposición, liderada por el PSDB, se mantuvo en un estado de campaña permanente, reproduciendo la vigorosa crispación electoral de los meses anteriores. Más allá de su papel habitual, pasó a rechazar las propias reglas del juego, con un pedido de verificación del resultado de las elecciones que amenazaba poner al país en una situación de incertidumbre institucional tras años de relativa estabilidad y confianza mutua.

No obstante, el PSDB no sería el problema más grande de Dilma en 2015. La agenda de reformas para sacar a Brasil de la crisis tendría que ser negociada con el Congreso más fragmentado de la historia política del país: 28 partidos lograron elegir algún diputado federal en 2014; siendo el PT y PMDB (Partido do Movimento Democrático Brasileiro) núcleos del gobierno, tenían juntos solo $26 \%$ de los diputados y $37 \%$ de los senadores. En el inicio de la legislatura (febrero), el PT y el gobierno hicieron su apuesta más arriesgada, desastrada y de consecuencias más duraderas. Con la intención de disminuir la dependencia en relación con el PMDB (partido del vicepresidente del país, Michel Temer, y de los presidentes de Cámara y Senado), lanzaron una candidatura oficial (un diputado petista) a cargo del presidente de la Cámara de Diputados, a despecho de la condición de favorito de Eduardo Cunha (PMDB), político conservador que reflejaba un perfil cada vez más dominante en el poder legislativo brasileño. La interlocución entre Ejecutivo y Legislativo se quedaría aún más intrincada tras la fácil victoria de Cunha -no solo porque este cobraría su venganza personal a lo largo del año, pero también 
porque el PT se quedaría aislado en la Cámara, sin participación en la Mesa Directiva. La Cámara posee una estructura decisoria bastante centralizada; la Mesa, en conjunto con el Colegio de Líderes, son los órganos responsables por decidir lo que irá para la apreciación del plenario. De esa manera componen el núcleo de las decisiones más importantes de la Cámara, central para el control del proceso legislativo (Figueiredo y Limongi, 1999; Amorim, Cox y Mccubbins, 2003).

Sin embargo, el aislamiento del PT no era solo en la Mesa Directiva. Algunos de sus aliados más tradicionales -como el Partido Socialista Brasileño (PSB) y el Partido Democrático Trabalhista (PDT) - y otros más importantes para la gobernabilidad (como el PMDB), se alejaban de un partido con una imagen desgastada, sintiendo un olor de final de ciclo político y preparando el terreno para el 2018. Al mismo tiempo el PT abandonaba y fustigaba su propio gobierno, ensimismándose en la esperanza de un retorno triunfal de Lula en 2018. En medio de tales turbulencias, la Operación Lava Jato (conducida desde 2014 por Policía Federal y Ministerio Público Federal) desvelaba un gigantesco esquema de corrupción en la estatal Petrobras, comprometiendo nombres de todo el espectro de la elite política brasileña, muchos de ellos íntimos a los gobiernos petistas. El involucrar a la principal compañía y a las más grandes constructoras del país (Odebrecht, OAS, Camargo Correia, Andrade Gutierrez, entre otras) produjo un efecto dominó que contribuyó a deteriorar la situación económica. El aislamiento, con niveles récord de reprobación popular y el empeoramiento de los indicadores económicos (como se verá más adelante) estuvieron acompañados por el proceso de impeachment que rondó a la Presidenta a lo largo del año -alimentado explícitamente primero por Cunha y después, de manera más velada, también por su propio vicepresidente, Temer, quien articulaba con la oposición un gobierno de transición sin Dilma ni el PT-. En las calles, movimientos favorables y contrarios al gobierno disputaban espacios y atención de los medios de comunicación, con el ápice de las protestas en marzo.

Como se ha señalado arriba, la crónica de 2015, que empieza en 2014, podría ser resumida en la palabra crisis. Las crisis económica y política se alimentaban mutuamente; las revelaciones a cuentagotas de la Operación Lava Jato nutrían a ambas. En conjunto llevaron el país a una situación de espera e incertidumbres, al paralizar el principal polo decisorio del sistema político brasileño -el Ejecutivo federal-. En lenguaje cortazariano, la presidencia Dilma trató más bien de salvar el armario, que de ordenarlo.

Para comprender los fundamentos más importantes de estas crisis, tanto en términos económicos como políticos, es necesario ir más allá de la narrativa de los hechos más relevantes de 2015. Considerando la dificultad de hacerlo todavía desde el calor de los hechos, este artículo hace una primera tentativa. La sección siguiente presenta el comienzo político de 2015, con los resultados de las elecciones de 2014. La tercera sección discute la crisis económica, exhibiendo algunos datos que sitúan el año de 2015 como el peor de la era petista (2003-). La cuarta sección aborda las relaciones entre Ejecutivo y Legislativo, la parálisis de la presidencia frente a la amenaza de impeachment, y el hiperactivismo del legislativo. La sección final discute algunas de las implicaciones de la crisis en términos de calidad de la democracia y retos de los próximos años. 


\section{ELECCIONES DE 2014: EL COMIENZO POLÍTICO DE 2015}

La campaña electoral fue marcada por problemas que gobierno y el PT tuvieron que enfrentar con las investigaciones en relación con Petrobras, tras la Operación Lava Jato. A finales de julio de 2014 el Tribunal de Cuentas de la Unión (TCU) condenó a directores y exdirectores de Petrobras a devolver 1,6 mil millones de reales (aproximadamente 720 millones de dólares en valores de aquella época) por perjuicios advenidos en la compra de la Refinería de Pasadena (Estados Unidos). Además de eso, el fantasma de la inflación, el bajo crecimiento económico y el alza del dólar eran una realidad que el gobierno debería superar en plena disputa electoral. Aparte de estos problemas, el primer gobierno de la petista había encontrado otros siete ministros acusados de corrupción, la insatisfacción con la política y con los servicios públicos, que culminaron con las manifestaciones de junio del 2013, y la detención de importantes miembros del PT resultante del juicio del mensalão (Borba, Veiga y Martins, 2015). ${ }^{1}$

En el inicio de la corrida electoral en julio de 2014, tres candidatos principales disputaban el cargo de presidente: Dilma Rousseff, candidata a la reelección por el PT, Aécio Neves (exgobernador de Minas Gerais, y senador) por el PSDB, y Eduardo Campos, presidente del PSB y exgobernador de Pernambuco. La popularidad de Dilma, aunque nunca igual a las tasas anteriores a las manifestaciones callejeras de junio de 2013, sustentaba las previsiones acerca de su condición de favorita (Gráfico 1).

Gráfico 1. Tasas de aprobación popular de Dilma Rousseff, 2011-2015 (\%)

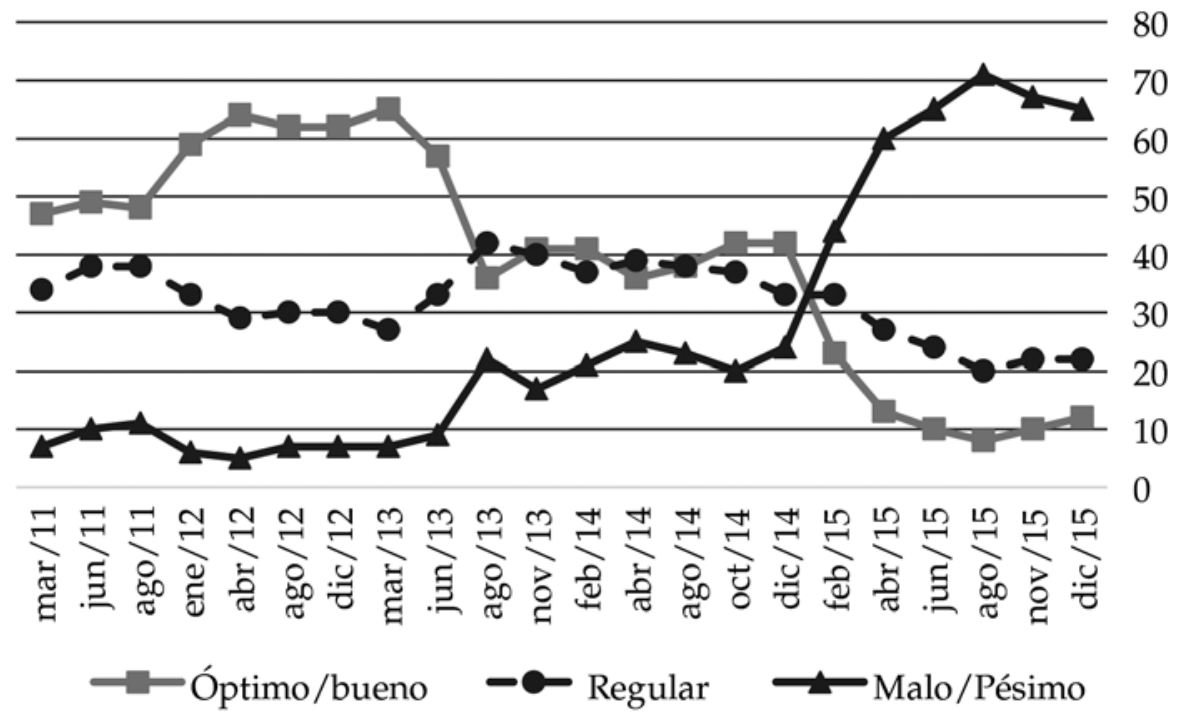

Fuente: Instituto Datafolha.

1 Entre los 20 acusados y presos en el juicio del mensalão estaban: el expresidente del PT, José Genoino; el exministro de la Casa Civil, y también expresidente del partido, José Dirceu; y el extesorero nacional, Delúbio Soares. 
La muerte de Campos en un accidente de avión en agosto cambió el escenario. Su candidata a vicepresidente era Marina Silva, exsenadora por el PT y exministra del Medio Ambiente del gobierno Lula, que había arreglado un acuerdo con Campos tras la tentativa frustrada de legalización de su nuevo partido, la Red Sustentabilidad. Marina Silva entonces asumió la candidatura, y la conmoción nacional por el trágico accidente ayudó a impulsar sus números en las encuestas. En la última encuesta antes de su muerte, Campos tenía 8\% de intención de voto; en la primea encuesta con Marina a la cabeza, ella ya contaba con la preferencia de $21 \%$ del electorado -índice que llegaría a $24 \%$ a mediados de septiembre, en situación de empate técnico con Dilma Rousseff y abriendo ventaja en relación con Neves, que tenía solo 10\% de los votos-. Proyecciones sobre la segunda vuelta indicaban que Marina podría derrotar a la candidata oficial. ${ }^{2}$

Disputas mayoritarias reducen de manera efectiva el número de competidores, muchas veces por el alto costo de las disputas, lo que hace que los partidos adopten otras estrategias; y también por el electorado, que muchas veces vota en estos casos a candidatos con una posibilidad mayor de ganar las elecciones. Entre 1994 y 2010 la disputa presidencial en Brasil estuvo polarizada entre el PT y PSDB (Limongi y Cortez, 2010; Melo, 2015) y con el ingreso de Marina Silva al juego, el escenario parecía cambiar.

La campaña de Marina tuvo como uno de sus fundamentos discursivos el fin de la polarización PT-PSDB, con la idea de una tercera vía de perfil postmoderno, más allá de la polarización, de la división izquierda-derecha -como un paso adelante tras errores y aciertos de los gobiernos de Fernando Henrique Cardoso (PSDB, 1995-2002) y Lula/ Dilma (2003)-. Sin embargo, como en los comicios anteriores, la emergencia de un tercer candidato aparentemente importante no obtuvo éxito al final, y la polarización entre tucanos y petistas se mantuvo. Marina Silva perdió muchos votos por hacer una campaña confusa, cambiando su discurso algunas veces; además, su afiliación religiosa (evangélica) también generó algunas tensiones en su base electoral potencial, sobre todo en relación con temas como aborto, educación religiosa, etc. Su candidatura también sufrió por la fragilidad organizacional del PSB, por el poco tiempo de propaganda en TV y radio, y por la ausencia de aliados firmes en los estados, sobre todo candidatos a gobernador.

A despecho de las encuestas que apuntaban a una disputa entre Marina y Aécio por los electores insatisfechos con el gobierno y el PT, fue la campaña de Dilma Rousseff que emprendió los ataques más violentos contra la exministra de Lula, por considerarla con más potencial de crecimiento en la segunda vuelta. La campaña oficialista prometía la retomada del crecimiento y el mantenimiento de los programas y niveles de inversión en las políticas sociales (como el Bolsa Família y el programa de habitaciones populares "Mi Casa, Mi Vida"), sin mirar las restricciones fiscales. También propagandeaba que los dos principales candidatos de oposición extinguirían derechos de los trabajadores y algunos de los programas sociales de la era petista, en nombre de un severo ajuste fiscal.

Los ataques concentrados en Marina surtieron efecto: su candidatura se deshidrató en las últimas dos semanas en la misma proporción en que Aécio conquistaba más electores. 
Al final, Aécio obtuvo mayor éxito que la candidata del PSB (Tabla 1). A pesar de una participación importante en dos ciclos electorales (en 2010 obtuvo casi 20\% de los votos, por el Partido Verde), Marina Silva no logró quebrar la polarización PT-PSDB para la vuelta final. El candidato del PSDB atrajo la mayoría de los electores descontentos con el gobierno, mientras la votación en Marina se asoció a los descontentos con escolaridad más elevada y al electorado evangélico (Amaral y Ribeiro, 2015).

Tabla 1. Resultado de las elecciones presidenciales, $1^{\mathrm{a}}$ vuelta

\begin{tabular}{llcc}
\hline Candidato & \multicolumn{1}{c}{ Partidos de la coalición } & Votos & $\%$ \\
\hline Dilma Rousseff & $\mathrm{PT} / \mathrm{PMDB} / \mathrm{PSD} / \mathrm{PP} / \mathrm{PR} / \mathrm{PROS} / \mathrm{PDT} / \mathrm{PC}$ do B/PRB & 43.267 .668 & 41,6 \\
Aécio Neves & $\mathrm{PSDB} / \mathrm{PMN} / \mathrm{SD} / \mathrm{DEM} / \mathrm{PEN} / \mathrm{PTN} / \mathrm{PTB} / \mathrm{PTC} / \mathrm{PT}$ do B & 34.897 .211 & 33,5 \\
Marina Silva & $\mathrm{PSB} / \mathrm{PHS} / \mathrm{PRP} / \mathrm{PPS} / \mathrm{PPL} / \mathrm{PSL}$ & 22.176 .619 & 21,3 \\
\hline
\end{tabular}

Fuente: Tribunal Superior Electoral (TSE).

La disputa en la segunda vuelta fue bastante apretada, con una situación de empate técnico en casi todas las encuestas. Aécio Neves recibió el apoyo formal de Marina Silva y empezó una campaña más agresiva contra el gobierno. Con el regreso de la polarización, la campaña oficial insistió en comparaciones entre los gobiernos Fernando Henrique y Lula/Dilma. La radicalización llegó a las calles, con algunos enfrentamientos entre petistas y tucanos (sin mayores consecuencias). Al final, Dilma venció, principalmente por su performance en los estados de Nordeste (Tabla 2). La evaluación retrospectiva acerca del desempeño del gobierno fue el principal predictor del comportamiento electoral en la segunda vuelta (Amaral y Ribeiro, 2015).

Tabla 2. Resultado de las elecciones presidenciales, $2^{\mathrm{a}}$ vuelta

\begin{tabular}{|c|c|c|c|c|}
\hline \multirow{2}{*}{ Región } & \multicolumn{2}{|c|}{ Aécio - PSDB } & \multicolumn{2}{|c|}{ Dilma - PT } \\
\hline & Votos & $\%$ & Votos & $\%$ \\
\hline Norte & 3.376 .148 & 43,5 & 4.393 .301 & 56,5 \\
\hline Nordeste & 7.967 .846 & 28,3 & 20.176 .579 & 71,7 \\
\hline Centro-Oeste & 4.388 .594 & 57,4 & 3.254 .304 & 42,6 \\
\hline Sudeste & 25.470 .265 & 56,2 & 19.867.894 & 43,8 \\
\hline Sur & 9.686 .559 & 58,9 & 6.759 .908 & 41,1 \\
\hline Brasil & 51.041 .155 & 48,4 & 54.501 .118 & 51,6 \\
\hline
\end{tabular}

Fuente: TSE.

Las elecciones para gobernador apuntaron para una situación de mayor fragmentación partidista. En 2010, seis partidos conquistaron los cargos de gobernadores de los 26 estados y un distrito federal; en 2014, nueve partidos lo hicieron. 


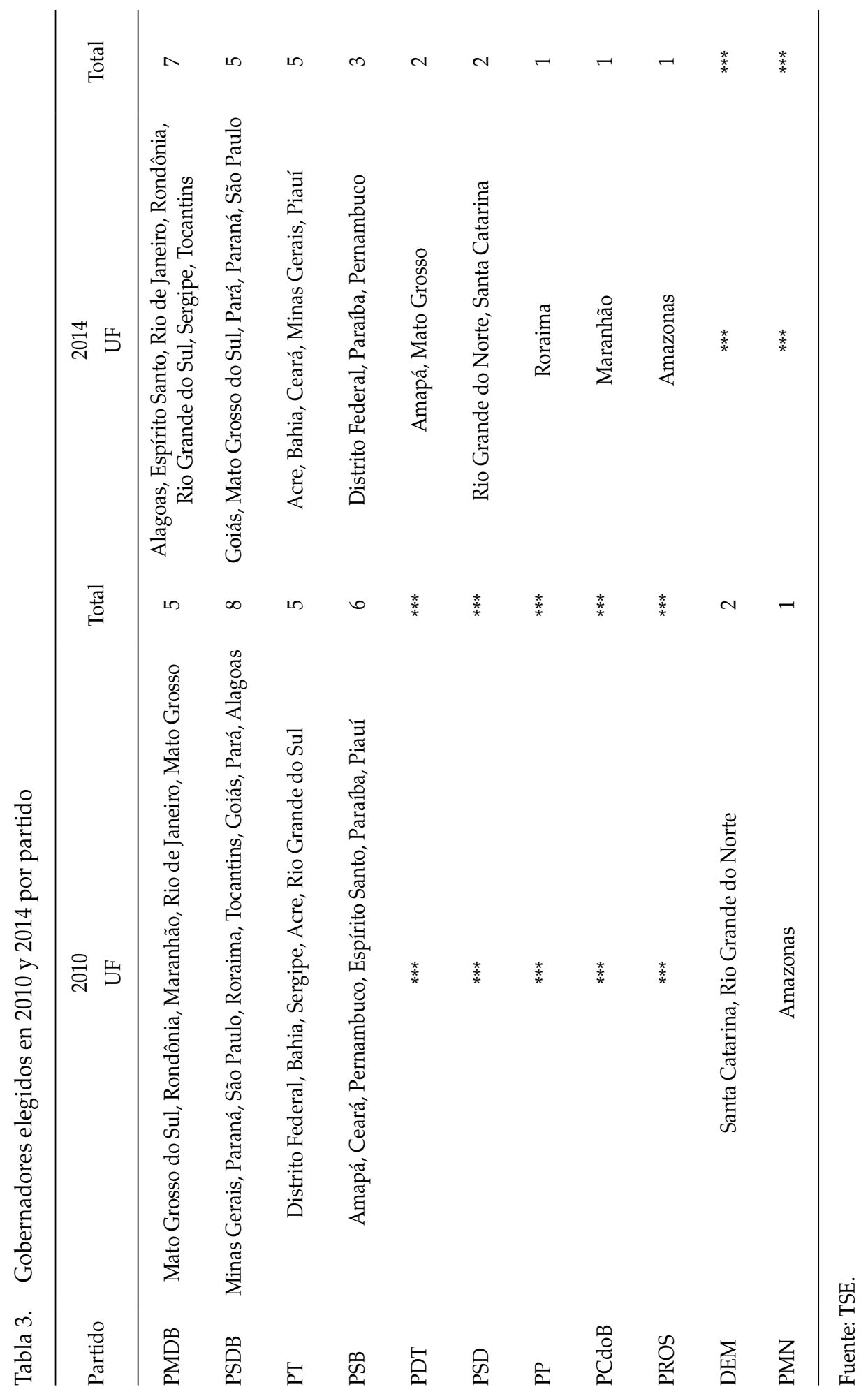


Los resultados de las elecciones legislativas apuntaban a que el gobierno tendría que utilizar diferentes estrategias políticas para hacer frente al crecimiento de la fragmentación partidista y a la pérdida de una cantidad significativa de asientos en la Cámara. En las Tablas 4 y 5 es perceptible el aumento del número de partidos pequeños. Ese crecimiento de las pequeñas siglas y el consecuente aumento de la fragmentación deben ser atribuidas, en parte, a dos factores: las coaliciones en la elección para los cargos legislativos proporcionales (diputados federales y estaduales, y concejales locales), que favorecen los partidos pequeños que forman alianzas con los grandes; y las decisiones del Supremo Tribunal Federal (STF) y del TSE con relación a la fidelidad partidista y a la división del fondo partidario y del tiempo de televisión, que acaban por incentivar la movilidad de la élite política entre los partidos y la creación de nuevos partidos (Santos et al, 2004: 39; Ribeiro, 2013). Tras los comicios de 2014, el número efectivo de partidos en la Cámara llegó a 13,3: como resultado, es el legislativo más fragmentado del mundo (Gallagher, 2015).

Tabla 4. Bancadas de los partidos en la Cámara de Diputados, 2010 y 2014

\begin{tabular}{|c|c|c|c|c|}
\hline \multirow{2}{*}{ Partidos } & \multicolumn{2}{|c|}{2010} & \multicolumn{2}{|c|}{2014} \\
\hline & $\mathrm{N}$ & $\%$ & $\mathrm{~N}$ & $\%$ \\
\hline PT & 88 & 17,2 & 69 & 13,5 \\
\hline PMDB & 78 & 15,2 & 65 & 12,7 \\
\hline PSDB & 53 & 10,3 & 54 & 10,5 \\
\hline PP & 44 & 8,6 & 38 & 7,4 \\
\hline PSD & $* *$ & $* *$ & 36 & 7,0 \\
\hline PSB & 34 & 6,6 & 34 & 6,6 \\
\hline PR & 40 & 7,8 & 34 & 6,6 \\
\hline РТВ & 22 & 4,3 & 25 & 4,9 \\
\hline PRB & 8 & 1,6 & 21 & 4,1 \\
\hline DEM & 43 & 8,4 & 21 & 4,1 \\
\hline PDT & 26 & 5,1 & 20 & 3,9 \\
\hline SD & $* *$ & $* *$ & 15 & 2,9 \\
\hline PSC & 17 & 3,3 & 13 & 2,5 \\
\hline PROS & $* *$ & $* *$ & 11 & 2,1 \\
\hline PPS & 12 & 2,3 & 10 & 1,9 \\
\hline PC do B & 15 & 2,9 & 10 & 1,9 \\
\hline PV & 14 & 2,7 & 8 & 1,6 \\
\hline PSOL & 3 & 0,6 & 5 & 1,0 \\
\hline PHS & 2 & 0,4 & 5 & 1,0 \\
\hline PTN & ** & $* *$ & 4 & 0,8 \\
\hline PRP & 2 & 0,4 & 3 & 0,6 \\
\hline PMN & 4 & 0,8 & 3 & 0,6 \\
\hline PEN & ** & $* *$ & 2 & 0,4 \\
\hline PSDC & ** & $* *$ & 2 & 0,4 \\
\hline PTC & 1 & 0,2 & 2 & 0,4 \\
\hline PTdoB & 4 & 0,8 & 1 & 0,2 \\
\hline PSL & 1 & 0,2 & 1 & 0,2 \\
\hline PRTB & 2 & 0,4 & 1 & 0,2 \\
\hline Total & 513 & 100,0 & 513 & 100,0 \\
\hline
\end{tabular}

Fuente: TSE. 
Tabla 5. Fragmentación de la Cámara de Diputados, 1982-2014

\begin{tabular}{lccccccccc}
\hline & 1982 & 1986 & $1989-90$ & 1994 & 1998 & 2002 & 2006 & 2010 & 2014 \\
\hline $\begin{array}{l}\text { Número efectivo de partidos } \\
\text { parlamentarios }^{1}\end{array}$ & 2,4 & 2,8 & 8,7 & 8,2 & 7,1 & 8,5 & 9,3 & 10,4 & 13,3 \\
Número de partidos nominales & 5 & 12 & 19 & 18 & 18 & 19 & 21 & 22 & 28 \\
\hline
\end{tabular}

Fuente: Melo (2007), actualizado por los autores para 2010 y 2014, con datos brutos del TSE. ${ }^{1}$ Según la fórmula de Laakso y Taagepera (1979).

La renovación de la Cámara de los Diputados fue de 46,8\%.3 Sin embargo, la nueva configuración de la Cámara Baja quedó más conservadora con el crecimiento de los segmentos religiosos, destacándose los protestantes evangélicos, que mantuvieron una bancada sólida compuesta por 74 diputados. Además, creció también el número de diputados de la bancada ruralista y de la "bancada de la bala" (grupo conocido por defender medidas más duras para combatir la criminalidad, como la reducción de la mayoridad penal, además del derecho a la posesión de armas de fuego). Más numerosas y articuladas, las tres bancadas forman lo que algunos llaman la "bancada BBB": buey, biblia y bala. Ya en el Senado, la renovación de un tercio no trajo grandes cambios en relación con la distribución partidista (Tabla 6).

Tabla 6. Bancadas de los partidos en el Senado, 2010 y 2014

\begin{tabular}{lcccc}
\hline Partido & $\begin{array}{c}\text { Elegidos para mandato } \\
2011-2019\end{array}$ & $\begin{array}{c}\text { Elegidos para mandato } \\
2015-2023\end{array}$ & Total & $\%$ \\
\hline PMDB & 14 & 4 & 18 & 22,2 \\
PT & 10 & 3 & 13 & 16,0 \\
PSDB & 7 & 4 & 11 & 13,6 \\
PP & 5 & 1 & 6 & 7,4 \\
PSB & 4 & 3 & 7 & 8,6 \\
PR & 3 & 1 & 4 & 4,9 \\
PDT & 2 & 4 & 6 & 7,4 \\
PSD & 2 & 2 & 4 & 4,9 \\
DEM & 1 & 3 & 4 & 4,9 \\
PCdoB & 1 & - & 1 & 1,2 \\
PPS & 1 & - & 1 & 1,2 \\
PRB & 1 & - & 1 & 1,2 \\
PSC & 1 & - & 1 & 1,2 \\
PTB & 1 & 2 & 3 & 3,7 \\
REDE & 1 & - & 1 & 1,2 \\
\hline Total & 1 & 27 & 81 & 100 \\
\hline
\end{tabular}

Fuente: TSE.

3 Según datos del DIAP, Departamento Intersindical de Asesoría Parlamentaria. Esos datos pueden ser consultados en “Radiografía do Novo Congreso - Legislatura 2015-2019”, disponible en línea: http:/ / www.diap.org.br/ index.php?option=com_jdownloads\&Itemid $=513 \&$ view $=$ finish\&cid $=2883 \&$ catid $=41$. 
En relación con la representación femenina, a pesar de que la legislación electoral exija de los partidos la presencia de por lo menos 30\% de mujeres en la lista electoral en las disputas proporcionales para el Legislativo (diputados y concejales), el crecimiento del número de mujeres elegidas se encuentra lejos del nivel esperado. En este sentido, aún existe un déficit de género cuando nos referimos a las mujeres en la política brasileña (Paiva, Sobrinho y Sara, 2011). Aunque no exista una cuota de género para sus candidaturas, el Senado tiene más mujeres que la Cámara (Tabla 7).

Tabla 7. Participación femenina en el Congreso Nacional

\begin{tabular}{lrrc}
\hline \multicolumn{4}{c}{ Cámara de Diputados } \\
\hline Comicios & Candidatas & Elegidas & $\begin{array}{c}\text { \% de mujeres sobre total de } \\
\text { elegidos }\end{array}$ \\
\hline 2010 & 935 & 45 & 8,8 \\
2014 & 1.765 & 51 & 9,9 \\
\hline & & Senado & 13,0 \\
\hline $2010^{*}$ & 29 & 7 & 18,5 \\
$2014^{* *}$ & 34 & 5 & \\
\hline
\end{tabular}

Fuente: TSE. *2010: renovación de dos tercios del Senado, que corresponde a 54 asientos. ${ }^{*} 2014$ : renovación de un tercio del Senado, o 27 asientos.

\section{LA CRISIS ECONÓMICA}

La Tabla 2 detalla el resultado final de las elecciones de 2014, las más apretadas de la historia política brasileña, con el candidato de la oposición venciendo en tres de las cinco regiones del país. Además del cansancio del electorado tras 12 años de PT y del castigo por los seguidos casos de corrupción, que comprometieron a los dirigentes del partido, fue también la creciente crisis económica que empezaba a cobrar su precio. El Brasil de la reducción de la pobreza, de la movilidad social y del desarrollo económico volvía a afrontar viejos fantasmas, como la recesión y el desequilibrio fiscal. Para suerte de Dilma, durante la campaña gran parte del electorado todavía no asociaba el gobierno con los problemas económicos que empezaban a aparecer con más fuerza -como la recesión y la inflación, que ya se anunciaban en mediados de 2014 (Gráficos 2 a 4)-. Según la encuesta postelectoral del ESEB (Estudio Electoral Brasileño), 46\% de los electores consideraban el gobierno como bueno u óptimo en noviembre de 2014 . Al mismo tiempo, eran pesimistas con relación al escenario económico: $28 \%$ decían que la economía había empeorado en los 12 meses anteriores, y 40\% creían que la disminución de ingresos de la familia era una situación "probable" o "muy probable" en los 12 meses siguientes (Amaral y Ribeiro, 2015).

Los gráficos abajo confirman las expectativas negativas. En 2015 el PIB brasileño tuvo una retracción de 3,8\% (en comparación a 2014), el peor resultado desde 1996. 
Gráfico 2. Variación trimestral del PIB, 2011-2015

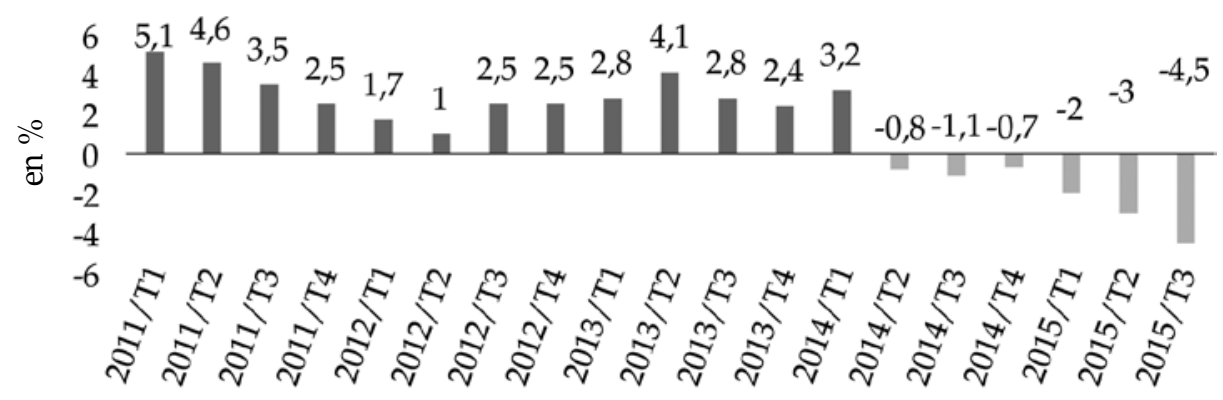

Trimestre

Fuente: Instituto Brasileño de Geografía y Estadística (IBGE).

Gráfico 3. Tasa de desempleo, 2011-2015

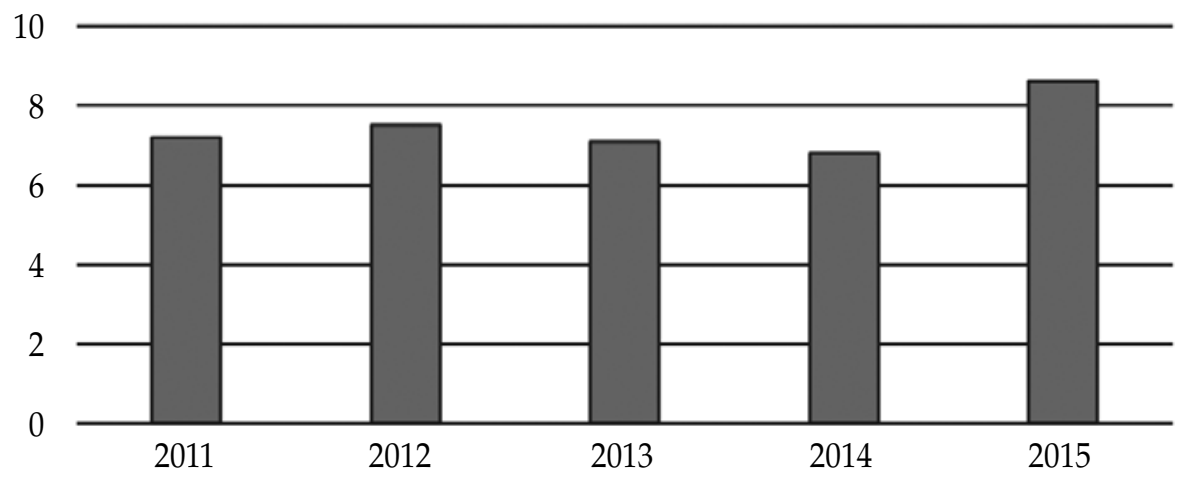

Fuente: IBGE (Pesquisa Nacional por Amostra de Domicílios, PNAD).

Gráfico 4. Tasa de inflación, 2003-2015

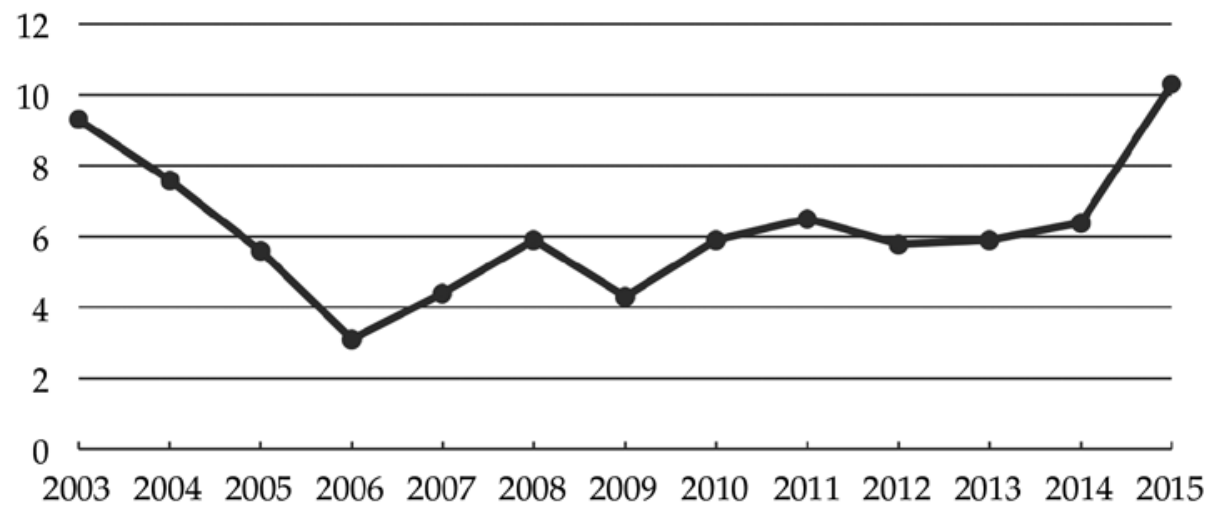

Fuente: IBGE (Índice Nacional de Preços ao Consumidor Amplo, IPCA). 
La situación fiscal del país ha sido muy delicada desde 2012: el Gráfico 5 demuestra la continua elevación de gastos del gobierno federal cuando ya ocurría una significativa disminución de la recaudación.

Gráfico 5. Variación real de ingresos y gastos federales, 2011-2015

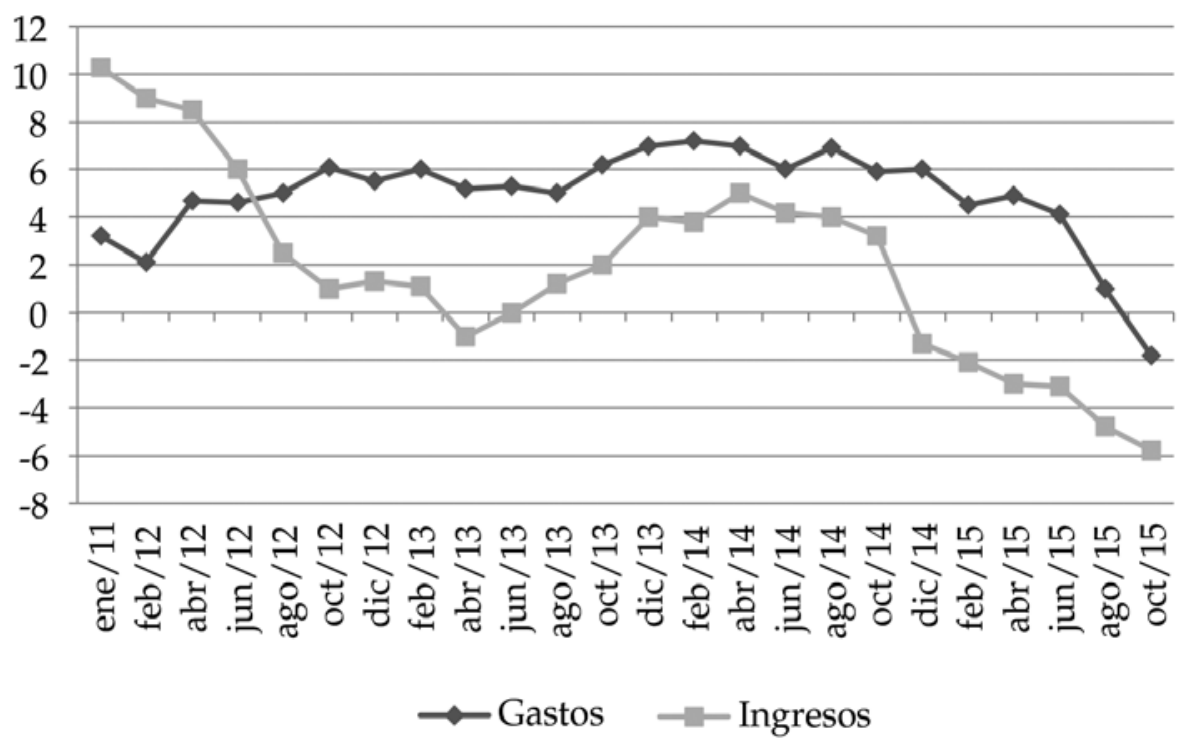

Fuente: Informes de la Secretaría del Tesoro Nacional. Gastos excluyen dividendos, concesiones, Petrobras y Fundo Soberano do Brasil (FSB); ingresos excluyen Petrobras y FSB.

El retraso en la aplicación de medidas para contener los gastos hizo explotar el déficit fiscal en 2015. En 2013, la relación deuda pública/PIB era de 51,7\%; los valores fueron 57,2\% en 2014 y 66,2\% en 2015, con la posibilidad de llegar a 80\% antes de 2018, si la diferencia entre ingresos y gastos se mantiene. ${ }^{4}$ La realidad fiscal del país suplantaría la retórica electoral pocas semanas después de los comicios, en la formación del nuevo gabinete de Dilma. El nombramiento de un ministro de Finanzas (Joaquim Levy), notoriamente adepto del recetario liberal de gestión macroeconómica, indicaba tanto que la situación fiscal era más preocupante de lo que ha admitido, como también que el gobierno ya planteaba un cambio de rumbo. El simbolismo de esta y de otras indicaciones frustró a gran parte de las bases que habían apoyado la reelección de Dilma, incluso dentro del PT.

Cuando se decidió cambiar el rumbo, las medidas restrictivas potencializaron la contracción de la actividad económica, y el 2015 confirmaría los pronósticos más pesimistas en relación con la actividad económica. Según los datos del Ministerio del Trabajo, el país 
perdió más de 1,5 millones de puestos de trabajo en $2015 .{ }^{5}$ Considerando los 13 años de gobiernos del PT (2003-2015), fue el peor año en términos de la economía nacional, en casi todos los indicadores que se pueden analizar.

\section{EJECUTIVO Y LEGISLATIVO: UN AÑO DE IMPASSE}

En la campaña electoral Dilma dialogó con una situación social y económica que ya no existía. Agradó a todos al decir que la crisis no llegaría al país, prometió controlar la inflación, mantener los derechos laborales y evitar reducción de gastos. La disonancia entre retórica electoral y los inevitables ajustes fiscales cobró su factura en 2015. La opinión pública no tardó en rechazar sus primeras medidas del segundo mandato -como demuestran los índices de reprobación popular del Gráfico 1-. La sensación de engaño electoral, además de continuas revelaciones de la Operación Lava Jato (sugiriendo conexiones entre desvíos de fondos y la campaña de reelección), minaron la credibilidad de Dilma, convirtiéndola en un lame duck precoz, ${ }^{6}$ sin capacidad de liderazgo, aun en las primeras semanas de su nuevo mandato. Esto proporcionó munición para la oposición "oficial" liderada por el PSDB; y para la cruzada personal de Eduardo Cunha (PMDB), el presidente de la Cámara que pasaría a manipular la amenaza de impeachment como recurso de chantaje contra el gobierno, a cambio de apoyo en el proceso de investigación por sospechas de corrupción contra él, que se desarrollaba en la Cámara. Aparte del impeachment, Cunha manejaba el apoyo de parte del PMDB y de otros partidos a la agenda del gobierno; y la aprobación de medidas contrarias a los intereses del gobierno -la llamada "agenda bomba", por generar más gastos públicos en un momento de ajuste fiscal-. Además, el PT, por arriesgar un enfrentamiento contra Cunha en la elección para la presidencia de la Cámara, quedó excluido de la Mesa Directiva -órgano que, en conjunto con el Colegio de Líderes, constituye el núcleo decisorio de la Cámara (Figueiredo y Limongi, 1999; Amorim, Cox y Mccubbins, 2003)-.

De esa manera se había creado el contexto perfecto para la desarticulación de la coalición del gobierno y la parálisis decisoria. En esta situación, con gran parte de las energías dirigidas para salvar el mandato de Dilma, el Ejecutivo pudo hacer muy poco en dirección a las reformas necesarias a la reactivación económica (como se verá más adelante).

\section{El gabinete de Dilma en 2015}

El presidencialismo de la coalición resume el modus operandi de las relaciones entre ejecutivo y legislativo en la actual democracia brasileña. La coalición en las elecciones, más algunos partidos que adhieren al gobierno después, forman la coalición del gobierno que asegurará la aprobación de medidas y proyectos. El nombramiento de indicados

5 Más informaciones en: http://agenciabrasil.ebc.com.br/economia/noticia/2016-01/brasil-fechou-15-milhao -de-vagas-com-carteira-assinada-em-2015.

6 Lame duck: término de la política estadunidense para una persona que continúa en sus funciones después de ya elegido su sucesor, y que se queda sin poderes, en la práctica, para la efectiva toma de decisiones. 
por los partidos para los ministerios y otros puestos en la máquina federal constituye un importante vector de recompensas, que puede variar de acuerdo con la influencia que una determinada cartera ejerce sobre las decisiones del gabinete. El tamaño de la bancada del partido es un factor decisivo para la cantidad de carteras ministeriales que podrá ocupar dentro del gabinete -lo que podemos observar claramente en la configuración ministerial de Dilma-. Conquistar una cartera como recompensa por el apoyo a la alianza se convierte en uno de los mecanismos de manutención del flujo continuo de incentivos que necesitan garantizar para fortalecer la propia estructura y competitividad dentro del sistema (Abranches, 1988; Figueiredo y Limongi, 1999; Inácio, 2013).

En la Tabla 8 abajo verificamos la formación de la base de apoyo en la Cámara y Senado en los dos mandatos de Dilma. Comparando los escenarios resultantes de los comicios de 2010 y 2014, se observa una disminución considerable de apoyo al gobierno en la Cámara de Diputados.

Tabla 8. Bloques de apoyo y oposición al gobierno tras las elecciones de 2010 y 2014

\begin{tabular}{|c|c|c|c|c|c|}
\hline & \multirow{2}{*}{ Partidos } & \multicolumn{2}{|c|}{ Cámara } & \multicolumn{2}{|c|}{ Senado } \\
\hline & & $\mathrm{N}$ & $\%$ & $\mathrm{~N}$ & $\%$ \\
\hline \multicolumn{6}{|c|}{ Tras las elecciones de 2010} \\
\hline Apoyo & $\begin{array}{l}\text { PT / PMDB / PP / PR / PSB / } \\
\text { PSC / PRB / PDT PTC / PCdoB }\end{array}$ & 351 & 68,4 & 55 & 67,9 \\
\hline Oposición & PSDB / DEM / PPS / PSOL & 111 & 21,6 & 19 & 23,4 \\
\hline Apoyo acondicionado & $\begin{array}{l}\text { PTB / PV / PMN / PTdoB / } \\
\text { PHS / PRTB / PRP / PSL }\end{array}$ & 51 & 9,9 & 7 & 8,6 \\
\hline \multicolumn{6}{|c|}{ Tras las elecciones de 2014} \\
\hline Apoyo & $\begin{array}{l}\text { PT / PMDB / PP / PSD / PR / } \\
\text { PRB / PDT PROS / PCdoB }\end{array}$ & 304 & 59,2 & 53 & 65,4 \\
\hline Oposición & $\begin{array}{l}\text { PSDB / PSB / PTB / DEM / SD } \\
\text { / PPS / PSOL PTN / PMN / } \\
\text { PEN / PTC / PTdoB }\end{array}$ & 176 & 34,3 & 27 & 33,3 \\
\hline Apoyo acondicionado & $\begin{array}{l}\text { PSC / PV / PH / PRP / PSDC / } \\
\text { PSL / PRTB }\end{array}$ & 33 & 6,43 & 1 & 1,2 \\
\hline
\end{tabular}

Fuente: Estudios Políticos del DIAP (Departamento Sindical de Assessoria Parlamentar) 2010/2014.

La primera formación del gabinete del segundo mandato de Dilma, nombrada en enero de 2015, contaba con 39 órganos divididos entre ministerios y secretarías. Con el pasar del año, Dilma hizo algunos cambios puntuales y, en octubre, realizó una gran reforma ministerial incluyendo la extinción y fusión de carteras y la sustitución de titulares de los ministerios. La reforma tenía dos objetivos: garantizar la permanencia de algunos 
partidos en la coalición de gobierno y responder a las presiones de la opinión pública por reducción de los gastos públicos y más eficiencia administrativa. En esta reforma, el Ministerio de la Seguridad Social y el Ministerio del Trabajo fueron unidos en la creación de un único ministerio. Las actividades del Ministerio de Pesca y Agricultura pasaron a pertenecer al Ministerio de Agricultura; la Secretaría de Asuntos Estratégicos fue extinta para disminuir gastos. Las Secretarías General, de Asuntos Institucionales y de Micro y Pequeñas Empresas fueron combinadas en la Secretaría del Gobierno. El gabinete de Seguridad Institucional no fue más considerado ministerio y también fue añadido a la Secretaría del Gobierno. Con la fusión de las Secretarías de Derechos Humanos, de Políticas Públicas para las mujeres, y de Políticas de Promoción de Igualdad Racial fue creado el Ministerio de Mujeres, Igualdad Racial y Derechos Humanos. En diciembre otros cambios fueron realizados. Tras meses de presiones por parte del PT, centrales sindicales y movimientos sociales, el Ministro de Finanzas Joaquim Levy fue sustituido por Nelson Barbosa, exministro entre 2011 y 2013, conocido por instituir un sistema económico menos liberal y de mayor intervención estatal.

En el cuadro de cambios ministeriales que encierra el año de 2015 (Tabla 9), los ministerios están distribuidos entre los partidos de la coalición y dos partidos considerados de apoyo condicional (PV y PTB). En su tentativa de garantizar el apoyo del PMDB, Dilma concedió más espacio al partido en el gabinete, en detrimento del PT -lo que desgastó aún más las relaciones entre Dilma y su partido, y entre el PT y PMDB-.

Tabla 9. Partidos gubernistas y sus ministerios

\begin{tabular}{|c|c|c|c|c|}
\hline & \multicolumn{4}{|c|}{ Ministerios* } \\
\hline & \multicolumn{2}{|c|}{2014} & \multicolumn{2}{|c|}{2015} \\
\hline & $\mathrm{N}$ & $\%$ & $\mathrm{~N}$ & $\%$ \\
\hline PT & 12 & 30,7 & 8 & 25,8 \\
\hline PMDB & 5 & 12,8 & 7 & 22,5 \\
\hline PCdoB & 1 & 2,5 & 1 & 3,2 \\
\hline PP & - & - & - & - \\
\hline PSD & 1 & 2,5 & 1 & 3,2 \\
\hline PDT & 2 & 5,1 & 1 & 3,2 \\
\hline PR & 1 & 2,5 & 1 & 3,2 \\
\hline PROS & - & - & - & - \\
\hline PRB & 1 & 2,5 & 1 & 3,2 \\
\hline $\mathrm{PTB}^{* *}$ & - & - & 1 & 3,2 \\
\hline Total & 23 & 58,9 & 21 & 67,7 \\
\hline
\end{tabular}

* Fuente: datos disponibles en la dirección electrónica del Palacio del Planalto. Diciembre fue usado como fecha base: 39 ministerios en 2014 y 31 en 2015. El total es más pequeño porque algunos ministerios no son encabezados por liderazgos partidistas. ${ }^{* *}$ El PTB pertenece al grupo de apoyo acondicionado. 
La crisis entre el PT y PMDB confluyó para un estremecimiento de las relaciones entre Dilma y el vicepresidente Michel Temer -que abordó sus insatisfacciones con la Presidenta en una quejumbrosa carta dirigida a ella en diciembre, en el ápice de la discusión sobre el impeachment-. La carta se hizo pública en el mismo momento, y el gesto de Temer -presidente del PMDB- fue interpretado como una seña más para el divorcio entre su partido y el PT.

\section{La agenda del Ejecutivo}

Los principales puntos de la agenda del gobierno Dilma en 2015 hacían parte del paquete de ajuste fiscal enviado al Legislativo. En el plan de ajuste, el gobierno aumentó los impuestos y redujo algunos beneficios sociales, además de congelar los gastos no obligatorios, llamados de "gastos discrecionales". Las medidas de austeridad7 incluían ajustes en la seguridad social con endurecimiento de reglas para beneficios como seguro de desempleo, pensión por muerte o invalidez parcial, y la actualización del fondo de garantía salarial. ${ }^{8}$ Las reglas de la seguridad social para las pensiones también fueron modificadas, siendo aumentados progresivamente el tiempo de cotización necesaria y la edad mínima para tener acceso al beneficio. Las alteraciones en los derechos de los trabajadores no fueron solamente de cortes. El punto positivo de las reformas fue la reglamentación de los derechos de los trabajadores domésticos, que por años esperaban por leyes que les protegieran.

Medidas directamente relativas a la economía también fueron hechas. Hubo un ajuste en el impuesto sobre la renta con la intención de aumentar los ingresos en todas las bases de cotización. Además, algunos cortes drásticos en políticas públicas son esperados para 2016. ${ }^{9}$ Las reducciones más relevantes ocurrieron en la Salud (que en 2015 representa 37\% de los gastos, y en 2016 será 35\%), en la Educación (de 14,4\% para $13,3 \%$ ) y en el Desarrollo Social (de 13,5\% para 12,9\%). El déficit en las cuentas públicas afectará programas sociales que son característicos del gobierno Dilma, como el programa "Mi Casa, Mi Vida" y el "Ciencia sin Fronteras". En principio, el programa Bolsa Familia, conocido como uno de los responsables por reducir la pobreza y la desigualdad social en el país en la última década, no sufriría cortes.

Sin embargo, la desarticulación de la coalición gubernamental en el Congreso impidió la adopción de otras medidas consideradas decisivas por el Ejecutivo para el equilibrio de las cuentas públicas y la reactivación económica. Una reforma más substantiva y amplia del sistema de seguridad social, así como la tentativa de recreación de la Contribución sobre Movimientos Financieros (CPMF), fueron postergadas para 2016; y el Senado hizo retornar al Ejecutivo una medida provisoria que también buscaba, en marzo de 2015, aumentar la recaudación por medio de elevaciones en las alícuotas de contribuciones de seguridad social pagadas por las empresas. La principal muestra de que el Ejecutivo

\footnotetext{
Datos disponíbles en los documentos del Palácio do Planalto.

El Fondo de Garantía por Tiempo de Servicio, FGTS.

Medidas anunciadas en comunicado oficial del equipo financiero del Gobierno Federal.
} 
no tenía control de la agenda política también vino del Senado: en agosto, su presidente Renan Calheiros (PMDB) articuló y presentó una lista de propuestas para afrontar la crisis económica: la "Agenda Brasil". A despecho de la irrelevancia práctica (ya que pocas propuestas han avanzado), el caso demuestra cómo el ejecutivo no tenía el control de la discusión sobre los caminos para que el país saliera de la crisis.

Otra preocupación del gobierno y del Congreso fue la aprobación de una minirreforma política para responder a la insatisfacción popular demostrada en las protestas de junio de 2013. Dilma sancionó, en octubre de 2015, la Ley N $N^{\circ} 13.165$ que dictaminó los cambios establecidos en el proyecto de reforma política, ya aprobado por el Congreso en los meses anteriores. Los principales cambios se refieren a las reglas que pueden reducir los gastos de campañas y aumentar la transparencia y punición en casos de crímenes electorales. Fueron también alteradas las normas que rigen el tiempo, el período, el estilo y los gastos de las campañas, así como la participación de los candidatos en el debate televisivo. Las reglas de afiliación y fidelidad al partido también sufrieron cambios y la sanción por desaprobación de cuentas de campañas o por la no prestación de cuentas pasó a ser exclusiva para los candidatos acusados, y no más para partidos.

La parte más polémica de la reforma discutía acerca de la cuestión del financiamiento empresarial de las campañas. El texto salió del Congreso permitiendo que tal financiamiento permaneciera. Sin embargo, en septiembre de 2015 el Supremo Tribunal Federal juzgó una acción propuesta por el Orden de Abogados de Brasil (OAB) en que declaró inconstitucional la donación de empresas a los candidatos, vedando estas contribuciones de personas jurídicas. Con la garantía de la acción jurídica del Supremo, Dilma vetó el artículo que institucionalizaba ese tipo de donación, considerado una de las principales fuentes de corrupción en Brasil -en función de sospechoso origen ilícito, de violación de límites establecidos para el financiamiento, o en casos como la sospecha de que las donaciones estén vinculadas a favores por parte de los representantes políticos (Speck, 2005)-.

Con el objetivo de responder a las aspiraciones de la población respecto del tema, en marzo de 2015 Dilma anunció un paquete de medidas anticorrupción con proyectos que ya estaban siendo analizados en el legislativo, además de algunas nuevas propuestas elaboradas por el ejecutivo. Sin embargo, hasta el cierre de 2015 el paquete no había sido votado por el Congreso. Delante de la brecha, procuradores del Ministerio Público Federal, asumiendo el carácter de "poder judiciario legislador", formularon un paquete anticorrupción complementario al proyecto del gobierno. ${ }^{10} \mathrm{Al}$ fin de 2015 el proyecto del MPF ya contabilizaba con más de un millón de firmas que requerían su análisis y aprobación por el Congreso. 


\section{Un Legislativo no cooperativo}

La relación Ejecutivo-Legislativo es funcional en Brasil, principalmente por los poderes del Presidente de la República (poderes legislativos y de agenda, además de recursos institucionales que incentivan la cooperación de los parlamentarios) y por el papel desempeñado por los líderes de las bancadas partidistas en Cámara y Senado (Figueiredo y Limongi, 1999). Sin embargo, la dificultad del control por parte del gobierno Dilma sobre el Congreso, frente a la coyuntura política de 2015, quedó evidente. No solamente la crisis económica, pero la crisis política generada por el embate entre PT, Eduardo Cunha y PMDB, trajo, entre otros problemas, dificultades para el gobierno conseguir implementar su agenda. Las tasas de apoyo al gobierno en las votaciones nominales ocurridas en la Cámara de diputados en 2015 son considerablemente más pequeñas, si comparamos con el año inaugural del primer gobierno Dilma (Tabla 10). Ni la transferencia de las funciones de articulación política para el vicepresidente Temer ayudó en la tarea de reorganizar la coalición de gobierno.

Tabla 10. Tasas de apoyo al gobierno de los partidos de la base (en \%)

\begin{tabular}{lcc}
\hline Partidos & 2011 & 2015 \\
\hline PMDB & 92 & 75 \\
PTB & 92 & 69 \\
PSD & 95 & 72 \\
PP & 92 & 61 \\
PR & 85 & 80 \\
PT & 96 & 94 \\
PROS & - & 80 \\
PDT & 84 & 70 \\
PCdoB & 95 & 85 \\
PRB & 90 & 81 \\
\hline
\end{tabular}

Fuente: Estadão Dados - Basômetro. Votaciones 2015: referentes al período de 10/02/2015-15/12/2015. Total de 215 votaciones. Votaciones 2011: referentes al período de 15/02/2011 - 14/12/2011. Total de 82 votaciones.

Entre las grandes derrotas del gobierno en la Cámara en 2015 están la reducción de la edad penal para crímenes graves; el texto principal acerca de la ampliación de la tercerización en el país; el reajuste de los beneficios de pensión y el aumento de los sueldos de diversas carreras públicas, contribuyendo para el crecimiento de los gastos públicos; y la dificultad en la aprobación de medidas que elevaban la recaudación fiscal.

Los escándalos de corrupción de Petrobras y el fantasma del proceso de destitución fueron algunos de los ingredientes que ayudaron a debilitar el control del gobierno sobre la Cámara. Por otro lado, los equívocos y la incapacidad de articulación política del gobierno, al apostar en el enflaquecimiento del PMDB, pueden ser considerados 
el origen de gestación de una presidencia hostil en la Cámara, bajo Eduardo Cunha (PMDB). A partir de mediados del año, acusado por incumplimiento de las normas al decoro parlamentario y envolvimiento en el esquema de corrupción en Petrobras, Cunha adoptó el camino de la ruptura y radicalización contra el gobierno. En octubre de 2015 pasó a contar con un activo valioso: la reprobación, por el TCU, de las cuentas del gobierno Dilma referentes a 2014, por la práctica de las llamadas pedaladas (pedaleos) fiscais. Según los auditores, el ejecutivo había manipulado las cuentas públicas (usando los bancos oficiales) con el objetivo de camuflar la situación fiscal del país. El tribunal así recomendaba que el Congreso debería reprobar tales cuentas (la decisión quedó para 2016).

Tras semanas de chantaje e impase político, el PT retiró el apoyo al diputado en los procesos dentro del legislativo; acto continuo, Cunha aceptó, en diciembre de 2015, uno de los pedidos de apertura de proceso de impeachment registrados contra Dilma Rousseff. La principal tesis del pedido era que la práctica de los pedaleos continuaba en 2015, contrariando la Ley de Responsabilidad Fiscal y así justificando el impeachment por improbidad administrativa. Contribuyendo para la escalada de la tensión, el líder del gobierno en el Senado, senador Delcídio Amaral (PT), fue arrestado en el ámbito de la Operación Lava Jato, por sospechas de envolvimiento en la corrupción en Petrobras.

Pocos días después, la sesión para elegir los diputados que asumirían los puestos en la Comisión de la Cámara responsable por analizar el pedido de destitución fue marcada por gran tumulto. La decisión de Cunha por una votación secreta resultó en urnas rotas y confrontación entre gobernistas y opositores. Por 272 votos contra 199, la lista dominada por la oposición fue electa a componer la Comisión. Sin embargo, el llamado "rito de la destitución" adoptado por Cunha fue anulado por decisión del Supremo Tribunal Federal. En ese aspecto, hay que destacar el papel que el Poder Judiciario ha desarrollado en Brasil. El sistema judiciario y las instituciones autónomas (Tribunal de Cuentas y Ministerio Público) recibieron amplios poderes en la Constitución de 1988 y se convirtieron en protagonistas en los últimos años, consolidándose como actores importantes en el sistema político brasileño (Melo y Pereira, 2013). ${ }^{11}$

Este escenario de completa desarticulación de la coalición de gobierno y de tensión entre ejecutivo y legislativo, inédito en la democracia brasileña desde el gobierno Collor de Melo (1990-1992), paralizó la agenda del Ejecutivo. Por otro lado, culminó en un año de hiperactividad del Legislativo, ya sea por la aceleración en los trámites referentes a proyectos contrarios a los intereses del gobierno (la "agenda bomba"), por la habilidad de Cunha de llevar adelante proyectos de interés de su base particular en la Cámara (diputados del llamado "bajo clero"), o por la actuación concertada y proactiva de las bancadas suprapartidistas más conservadoras, que constituyeron un grupo más

11 Cuando este artículo fue encerrado, Cunha aún se mantenía en la presidencia. Sobre las acusaciones contra él, después de muchos preámbulos, la Comisión de Ética de la Cámara aprobó el informe para dar continuidad en las investigaciones contra el deputado por incumplimiento de las normas al decoro parlamentario. 
articulado y numeroso a partir del inicio de la actual legislatura -religiosos, ruralistas y la "bancada de la bala"-. La Tabla 11 demuestra el año atípico del legislativo brasileño. ${ }^{12}$

Tabla 11. Propuestas de legislación por autor, 2011-2015

\begin{tabular}{ccccccccc}
\hline & \multicolumn{2}{c}{ Cámara } & \multicolumn{2}{c}{ Senado } & \multicolumn{2}{c}{ Ejecutivo } & \multicolumn{2}{c}{ Total } \\
\cline { 2 - 9 } & $\mathrm{N}$ & $\%$ & $\mathrm{~N}$ & $\%$ & $\mathrm{~N}$ & $\%$ & $\mathrm{~N}$ & $\%$ \\
\hline 2011 & 3.388 & 70 & 964 & 20 & 510 & 10 & 4.862 & 100 \\
2012 & 2.022 & 63 & 635 & 20 & 573 & 18 & 3.230 & 100 \\
2013 & 2.331 & 64 & 755 & 21 & 564 & 15 & 3.650 & 100 \\
2014 & 1.450 & 58 & 554 & 22 & 494 & 20 & 2.498 & 100 \\
2015 & 4.878 & 76 & 1.027 & 16 & 477 & 7 & 6.382 & 100 \\
\hline
\end{tabular}

Fuente: Cámara de los Diputados, Senado Federal, Portal de la Legislación.

\section{CONSIDERACIONES FINALES}

El balance del 2015 muestra que Dilma Rousseff, después de haber sido democráticamente elegida por la mayoría del electorado, sufrió una crisis de legitimidad eminentemente política, en un sentido amplio de la palabra. La disonancia entre las promesas de campaña y las acciones iniciales del mandato; nuevas revelaciones relativas al esquema de corrupción en Petrobras; los equívocos y la inhabilidad política en las articulaciones con otros actores -sobre todo el Legislativo-; y la escalada de malas noticias acerca del ambiente económico, fueron los factores que, combinados, plasmaron una rara situación de crisis aguda. De esa manera, establecido un círculo vicioso entre las diferentes crisis, pocos meses después de la elección Dilma tenía una popularidad de alrededor del 10\% y muchos actores políticos y sociales relevantes hablaban abiertamente acerca de un proceso de impeachment.

El impeachment se impone, así, como modalidad recurrente de inestabilidad política en América Latina y, al mismo tiempo, como solución para impases y crisis presidenciales sin una ruptura democrática al estilo de los golpes militares (Pérez-Liñán, 2007). El bajo desempeño administrativo y económico, la formación de coaliciones hostiles en el Congreso, que dificultan su manejo por el Ejecutivo, la adopción de políticas impopulares y la actuación investigativa de los medios de comunicación en la divulgación de los casos de corrupción, son factores suficientes para la erosión de la popularidad presidencial (y para el abandono del Presidente por parte de sus apoyadores). A partir de esto, la capacidad del Legislativo para destituir al Presidente depende, sobre todo, de la movilización popular, con amplios y múltiples sectores de la sociedad marchando por las calles (Pérez-Liñán, 2007). Todas las condiciones iniciales se dieron en Brasil en 
2015. Sin embargo, las protestas dejaron dudas respecto de la amplitud del apoyo a la destitución de Dilma. Tras marchas multitudinarias en marzo, había la expectativa de ampliación del apoyo en agosto, cuando el impeachment ya estaba claramente en el orden del día. Con todo, las protestas a favor del gobierno fueron entonces tan grandes -o hasta más grandes- que las contrarias. En marzo de 2016 nuevas masivas protestas contra el gobierno y la corrupción tomaron las calles de las principales ciudades brasileñas -para algunos fueron las más grandes manifestaciones desde la redemocratización-. Los manifestantes eran, sin embargo, principalmente de la clase media, repitiendo el perfil identificado en 2015.13

La tentativa de la justificación del impeachment como una especie de "voto de desconfianza" al estilo parlamentarista (Pérez-Liñán, 2007) no prosperó en 2015. De cualquier manera, se puede afirmar que la acción pro-impeachment del presidente de la Cámara y de la oposición, encabezada por el PSDB, surge más bien como consecuencia que como causa de una amplia crisis política generada por las propias huestes gubernamentales. Tanto unos como otros se aprovecharon de una situación de fragilidad para intentar alcanzar sus objetivos. La amenaza de impeachment aparece, así, como recurso político de presión, negociación y movilización de la opinión pública, en las disputas de poder actuales y futuras: sea para obtener más espacio en el gabinete Dilma (PMDB y otros partidos de la coalición); para desestabilizar el gobierno, mantener sus bases movilizadas y conectarse a los sectores sociales más radicales y antipetistas, mirando hoy y las elecciones futuras (PSDB); para sobrevivir políticamente (Eduardo Cunha); o para alcanzar la presidencia por medio de un atajo (el vicepresidente Temer).

Además de la ausencia de la movilización popular, la actuación del Senado más favorable al gobierno, y del Poder Judicial revisando decisiones del legislativo, fueron factores que ayudaron al ejecutivo a sobrevivir en 2015. Estos factores, pero principalmente la acción del Poder Judicial a finales del año -frenando decisiones del presidente de la Cámara en relación con los trámites del impeachment- son ilustrativos de una de las principales fortalezas de la democracia brasileña hoy. Hasta hace poco, parte de la literatura consideraba la configuración institucional del sistema político brasileño como propensa a producir impases, crisis y parálisis decisoria, debido a la multiplicidad de veto players: bicameralismo, presidencialismo y separación de poderes, multipartidismo, federalismo, judiciario revisor, etc. (Mainwaring, 1999; Ames, 2003). Sin embargo, los múltiples actores de veto -incluyendo un Poder Judicial independiente y el Ministerio Público- han ayudado a chequear un Ejecutivo Federal que es sólido; y como demuestra el caso referido arriba, estos checks también se han dado sobre la acción del Legislativo (Melo y Pereira, 2013). El riesgo de impase existe, pero las ventajas de un sistema de múltiples check points son cada vez más evidentes.

Si las condiciones institucionales del presidencialismo de coalición no han cambiado, ¿cómo explicar la incapacidad del gobierno Dilma en las relaciones con el Legislativo

13 "Protesto cresce, mas manifestante mantém perfil de alta renda". Folha de S. Paulo, edición de 14 de marzo de 2016. http:/ / www1.folha.uol.com.br/poder/2016/03/1749640-protesto-cresce-mas-manifestante-mantemperfil-de-alta-renda.shtml. 
en 2015? El balance del año deja claro que el Legislativo brasileño no puede ser tomado como un actor pasivo y fácilmente controlable por un ejecutivo poderoso sobre la base de patronazgo y pork barrel. La configuración institucional del presidencialismo de coalición no engendra algo como una "ciencia exacta": en lugar de exclusión y sumisión del legislativo, existe una dimensión negociadora que no puede ser despreciada. En esta dimensión, el estilo del Presidente puede adaptarse menos o más a la morfología institucional predominante (Palermo, 2000). Aquí, es admisible señalar que Dilma Rousseff es la única presidenta de la actual democracia brasileña que llegó al Planalto sin nunca haber ocupado otro cargo público electivo. Sin una experiencia previa de negociación y articulación política, y con los principales cuadros del PT afectados por escándalos de corrupción, Dilma se encontró sola en la tarea de conducir la Presidencia como principal polo no simplemente decisorio, pero también negociador, del sistema político del país.

Los retos van a continuar en 2016: los escándalos de corrupción siguen apareciendo, y la economía llevará algún tiempo para presentar señales de recuperación. La orden de detención, en febrero último, contra el publicitario responsable por la campaña presidencial de 2014 por sospechas de haber recibido parte de sus pagos dentro del esquema de corrupción en Petrobras; y la conducción coercitiva de Lula por la Policía Federal en marzo, para interrogatorio sobre su presunta participación en el mismo caso mantienen el impeachment en la agenda, en dos frentes: el financiamiento de la campaña presidencial de 2014 y los "pedaleos" fiscales. En este escenario, Dilma tendrá que desdoblarse para garantizar la gobernabilidad y estabilidad; para esto necesitará no solo del PMDB, pero también de un PT que comprenda que el fracaso del gobierno será un fracaso del propio partido y de la izquierda brasileña postcomunista.

\section{REFERENCIAS}

Amaral, Oswaldo y Ribeiro, Pedro Floriano. 2015. “Por que Dilma de novo? Uma análise exploratória do Estudo Eleitoral Brasileiro de 2014". Revista de Sociologia e Política 23 (56): 107-123.

Ames, Barry. 2002. The Deadlock of Democracy in Brazil. Ann Arbor, Michigan: University of Michigan Press. Amorim Neto, Octavio, Cox, Gary y McCubbins, Matthew. 2003. "Agenda power in Brazil's Câmara dos Deputados, 1989-98". World Politics 55 (4): 550-578.

Abranches, Sérgio. 1988. "Presidencialismo de Coalizão: o dilema institucional brasileiro". Dados 31 (1): 5-38. Borba, Felipe de Moraes, Bozza Martins, Flávia y Veiga, Luciana. 2015. “Propaganda Negativa na Campanha Presidencial em 2014. Ou como tudo que é frágil se desmancha no ar". Revista Estudos Políticos: a publicação eletrônica semestral do Laboratório de Estudos Hum(e)anos (UFF) 6 (1): 171-189.

Departamento Intersindical de Assessoria Parlamentar (DIAP). 2015. "Radiografía do Novo Congreso Legislatura 2015-2019". En: http://www.diap.org.br/index.php?option =com_jdownloads \&Itemid $=513 \&$ view $=$ finish\&cid $=2883 \&$ catid $=41$.

Estadão Dados - Basômetro. 2015. “Tasa de apoyo de los partidos de base". En: http://estadaodados. com/basometro/.

Figueiredo, Argelina y Limongi, Fernando. 1999. Executivo e Legislativo na Nova Ordem Constitucional. Fundação Getúlio Vargas Editora, Rio de Janeiro.

Gallagher, Michael, 2015. "Election indices dataset". En: http://www.tcd.ie/Political_Science/staff/ michael_gallagher/ElSystems/index.php.

Inácio, Magna. 2013. "Escogiendo ministros y formando políticos: los partidos en gabinetes multipartidaristas”. América Latina Hoy 64: 41-66. 
Laakso, Markku. and Taagepera, Rein. 1979. "Effective" Number of Parties: A Measure with Application to West Europe'. Comparative Political Studies 12 (1): 3-27.

Limongi, Fernando y Cortez, Rafael. 2010. "As eleições de 2010 e o quadro partidário". Novos Estudos CEBRAP 88: 21-37.

Mainwaring, Scott. 1999. Rethinking Party Systems in the Third Wave of Democratization: The Case of Brazil. Redwood City: Stanford University Press.

Melo, Carlos Ranulfo. 2007. “Nem tanto ao mar, nem tanto a terra: elementos para uma análise do Sistema partidário brasileiro". En A democracia brasileira: balanço e perspectivas para o século 21, editado por C. R. Melo y M. Alcántara. Belo Horizonte: UFMG, 267-302.

2015. "The 2014 Elections and the Brazilian Party System". Brazilian Political Science Review, 9 (1): 93-114.

Melo, Marcos André y Pereira, Carlos. 2013. Making Brazil Work Checking the President in a Multiparty System. New York: Palgrave Macmillan.

Paiva, Denise; de Souza Mendonça Sobrinho, Milton y Gabriel Sara, Mariana. 2011. "Participação e representação feminina na política em Goiás - Notas de Pesquisa". Revista Debates 5 (2): 225-251.

Palácio do Planalto. 2016. "Ministérios do governo Dilma, primeiro e segundo mandato" En: http:/ / www2.planalto.gov.br/.

. 2016. “Nota oficial sobre ajuste fiscal e cortes no Orçamento". En: http://www2.planalto.gov.br/.

Palermo, Vicente, 2000. "Como se governa o Brasil? O debate sobre instituições políticas e gestão de governo". Dados 43 (3): 521-557.

Portal da Legislação. 2016. "Proposiciones del Ejecutivo". En: http:/ /www4.planalto.gov.br/legislacao.

Pérez-Liñán, Aníbal. 2007. Presidential Impeachment and the New Political Instability in Latin America. Cambridge: Cambridge University Press.

Ribeiro, Pedro Floriano. 2013. "Organização e poder nos partidos brasileiros: Uma análise dos estatutos". Revista Brasileira de Ciência Política 10: 225-265.

Santos, Fabiano et al. (2014). "A (con) figuração dos números eleitorais. Dos números eleitorais". Insight Inteligência 17 (67): 36-45.

Secretaria do Tesouro Nacional. (2016). "Informe sobre gastos del gobierno federal". En: http://www. tesouro.fazenda.gov.br.

Senado Federal. 2016. "Proposiciones de los senadores". En: http://www25.senado.leg.br/web/ atividade/legislacao.

Speck, Bruno. 2005. "Reagir a escândalos ou perseguir ideais? A regulação do financiamento político no Brasil". Cadernos Adenauer 6 (2): 123-159.

Pedro Floriano Ribeiro es doctor en Ciencia Política, es 'Celso Furtado Visiting Professor' en la Universidad de Cambridge (St John's College, 2015-16). Profesor e investigador del Departamento de Ciencias Sociales y del Programa de Postgrado en Ciencia Política de la Universidad Federal de São Carlos (Brasil). E-mail: pfribeiro@ufscar.br.

Amanda Vizoná con Maestría en Ciencia Política, es doctoranda en el Programa de Postgrado en Ciencia Política de la Universidad Federal de São Carlos (Brasil). E-mail: amanda_viz@hotmail.com.

Priscilla Leine Cassotta con maestría en Ciencia Política, es doctoranda en el Programa de Postgrado en Ciencia Política de la Universidad Federal de São Carlos (Brasil). E-mail: priscilla.leine@gmail.com. 


\section{ANEXO 1. \\ PARTIDOS POLÍTICOS BRASILEÑOS}

\begin{tabular}{|c|c|c|}
\hline & Sigla & Nombre \\
\hline 1 & PMDB & Partido do Movimento Democrático Brasileiro \\
\hline 2 & РТВ & Partido Trabalhista Brasileiro \\
\hline 3 & PDT & Partido Democrático Trabalhista \\
\hline 4 & PT & Partido dos Trabalhadores \\
\hline 5 & DEM & Democratas \\
\hline 6 & PCdoB & Partido Comunista do Brasil \\
\hline 7 & PSB & Partido Socialista Brasileiro \\
\hline 8 & PSDB & Partido da Social Democracia Brasileira \\
\hline 9 & PTC & Partido Trabalhista Cristão \\
\hline 10 & PSC & Partido Social Cristão \\
\hline 11 & PMN & Partido da Mobilização Nacional \\
\hline 12 & PRP & Partido Republicano Progressista \\
\hline 13 & PPS & Partido Popular Socialista \\
\hline 14 & PV & Partido Verde \\
\hline 15 & PTdoB & Partido Trabalhista do Brasil \\
\hline 16 & $\mathrm{PP}$ & Partido Progressista \\
\hline 17 & PSTU & Partido Socialista dos Trabalhadores Unificado \\
\hline 18 & PCB & Partido Comunista Brasileiro \\
\hline 19 & PRTB & Partido Renovador Trabalhista Brasileiro \\
\hline 20 & PHS & Partido Humanista da Solidariedade \\
\hline 21 & PSDC & Partido Social Democrata Cristão \\
\hline 22 & PCO & Partido da Causa Operária \\
\hline 23 & PTN & Partido Trabalhista Nacional \\
\hline 24 & PSL & Partido Social Liberal \\
\hline 25 & PRB & Partido Republicano Brasileiro \\
\hline 26 & PSOL & Partido Socialismo e Liberdade \\
\hline 27 & PR & Partido da República \\
\hline 28 & PSD & Partido Social Democrático \\
\hline 29 & PPL & Partido Pátria Livre \\
\hline 30 & PEN & Partido Ecológico Nacional \\
\hline 31 & PROS & Partido Republicano da Ordem Social \\
\hline 32 & SD & Solidariedade \\
\hline 33 & NOVO & Partido Novo \\
\hline 34 & REDE & Rede Sustentabilidade \\
\hline 35 & PMB & Partido da Mulher Brasileira \\
\hline
\end{tabular}

Fuente: Tribunal Superior Electoral (TSE). 